\title{
Bicondylar Hoffa fracture in a Young Male: A Rare Case
}

\author{
Arya $A^{1}$, Arya $S^{2}$, Jindal $\mathbf{M}^{3 *}$, Garg $\mathrm{A}^{4}$ and Sandhu $\mathbf{N}^{5}$ \\ ${ }^{1}$ Senior Resident, Department of Orthopedics', Kalpana Chawla Govt Medical College, India \\ ${ }^{2}$ Senior Resident, Department of Anesthesia, Kalpana Chawla Govt Medical College, India \\ ${ }^{3}$ Assistant Professor, Department of Orthopedics', Kalpana Chawla Govt Medical College, India \\ ${ }^{4}$ Senior Resident, Department of Medicine, VMMC \& SJH, New Delhi, India \\ ${ }^{5}$ Senior Resident, Department of Surgery, Kalpana Chawla Govt Medical College, India
}

Submission: August 08, 2019; Published: September 30, 2019

*Corresponding author: Mohit Jindal, Assistant Professor, Department of Orthopedics', Kalpana Chawla Govt Medical College, India

\begin{abstract}
Hoffa fractures are uncommon intra-articular fractures of femoral condyle in coronal plane. An isolated coronal fracture of either or both femoral condyles is a rare entity and is usually associated with high-energy injury trauma. We report the case of a patient who had a bicondylar Hoffa fracture which occurred as a result of a Road Traffic accident. It was treated with the functional and orthopedic approach. At follow- up of 3-month functional score was excellent with 90-degree flexion, an absence of laxity and an absence of pain. Through a review of the literature the mechanism, the diagnostic methods and therapeutic approach will be analyzed. Operative treatment of Hoffa fractures yields fairly good functional outcome. Such fractures should be meticulously fixed for a good functional outcome as they involve the articular surface of a weight bearing joint. One must endeavor to achieve adequate intraoperative exposure and stable congruous articular reconstruction. Swashbuckler approach provides adequate exposure for appropriate reduction and fixation of such fractures. Early aggressive physical therapy is a harbinger of optimal outcome
\end{abstract}

\section{Introduction}

The Hoffa fracture is a very uncommon fracture which is coronally-oriented fracture and extends through either the medial or lateral condyle of femur [1]. This fracture was first described by Friedrich Busch (1844-1916) and not as always assumed by Albert Hoffa in 1904. Although there is preponderance for lateral condyle, medial condyle involvement is not as uncommon as previously suspected. Lateral condylar split fractures are common because the usual mechanism of injury is axial transmission of ground reaction force directed posteriorly in a flexed knee joint. Rarely, due to direct impact over the knee may direct such force transmission to both condyles leading to a bicondylar Hoffa. There is a lack of concrete evidence in literature regarding these fractures. It is easy to diagnose but sometime can be very challenging because of poor X- ray quality or a non-displaced fracture. The management has come a long way from nonoperative treatment to anatomical reduction and internal fixation of these fractures. Here we are presenting a case of Bicondylar Hoffa fracture in a young male.

Patient and Observation

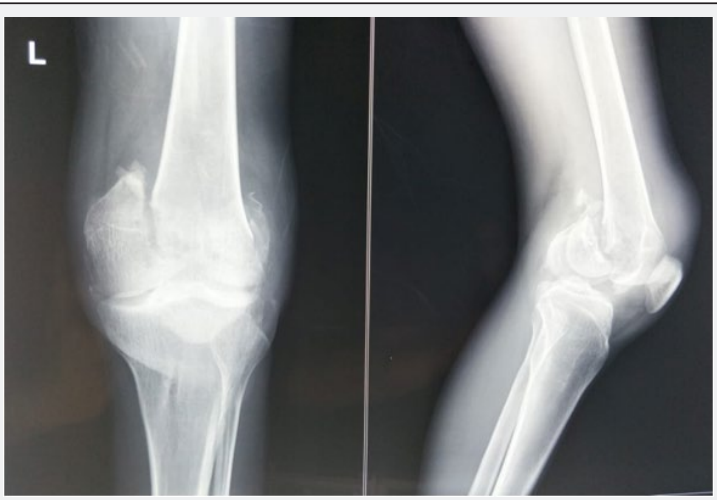

Figure 1: Antero-posterior and medio-lateral radiographs of Left knee joint showing Bicondylar Hoffa fracture. 
It was 26 years old male patient admitted to the Emergency Department for injury to left knee following a Road Traffic Accident which occurred about 1 month back. Patient went to a local bonesetter who applied splintage using cardboard and crepe bandage. It was a late presentation of injury and revealed painful swelling of the knee with hemarthrosis, more intense pain sitting at the level of the internal compartments of the knee. There was no neurovascular deficit or skin lesion. Because of the pain we had sought signs of laxity. The initial AP and lateral $\mathrm{x}$-rays showed a bicondylar Coronal fracture (Figure 1). The CT scan showed Coronal fractures type Hoffa of the both condyles (Figure 2).

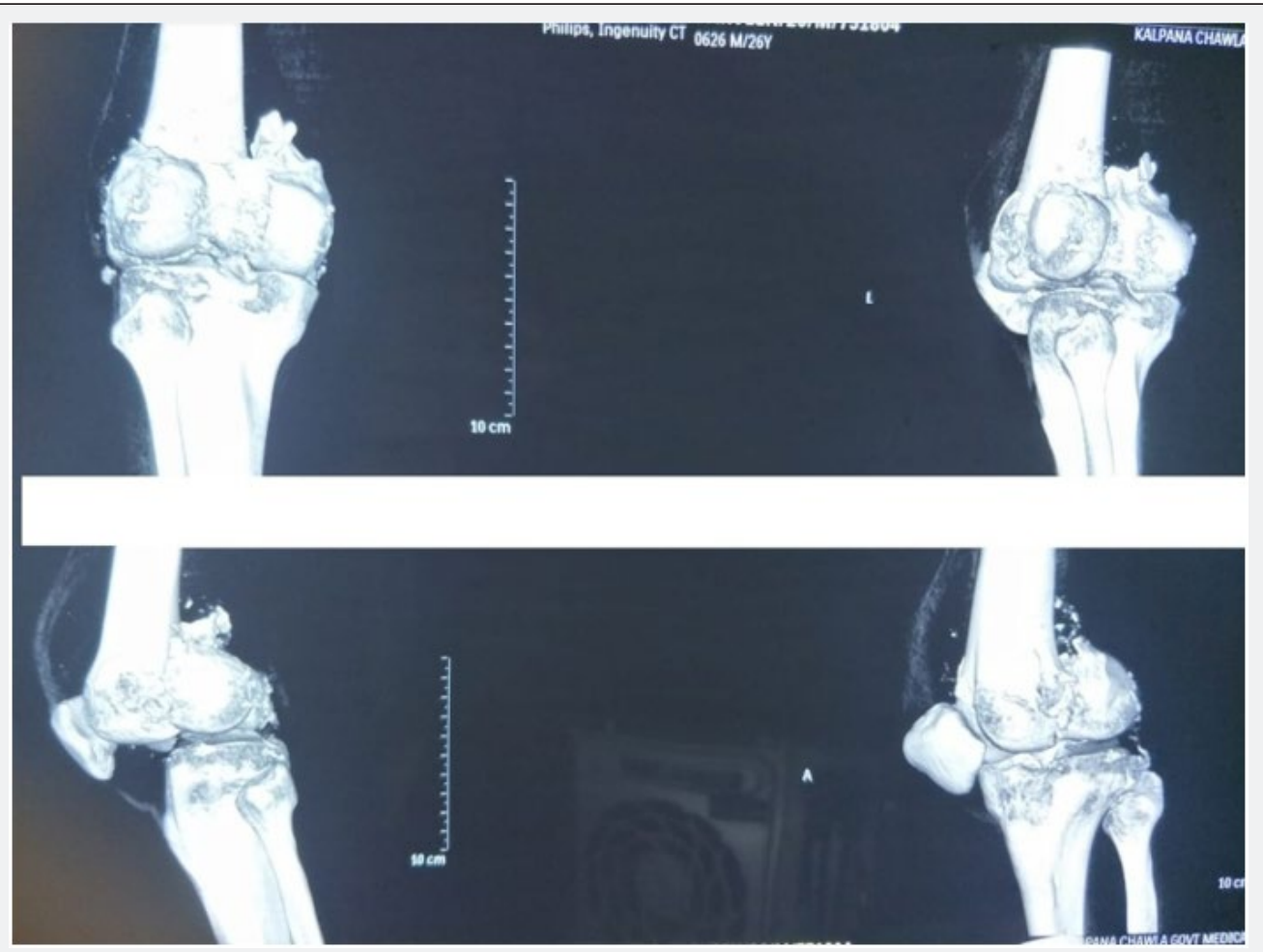

Figure 2: CT scan of Left knee had enabled the discovery of fracture pattern of medial and lateral femoral condyles

The patient support was primarily a functional method by a strict bed rest; knee was immobilized in knee brace. Locally we had carried out cryotherapy. Also, a medical treatment was associated with painkillers, of the anti-inflammatory and anticoagulant. Surgical treatment was carried out after thorough blood investigations and Pre-Anesthetic checkup. Since the fracture was involving both condyles, a conventional approach would not suffice and thus fracture fixation using Swashbuckler approach was planned. The Swashbuckler approach is a lateral approach extended distally between lateral patellar retinaculum and the vastus lateralis muscle to a lateral parapatellar arthotomy. The quadriceps muscle and patella are reflected medially to expose distal femur condyles.

We used proximal tibial plate on medial side and precontoured distal radius plate on lateral side along with $4.5 \mathrm{~mm}$ Cannulated cancellous screws to fix the fracture (Figure 3). Physiotherapy of the muscles was carried out. After the healing of skin lesions, we had immobilized knees by the cruro-pedious resins for 04 -week. At the end of this period, we proceed with the removal of the resin. The fact of removing is able to thaw the resumption of physical therapy for a period of 6 weeks. One follows up radiograph was undertaken externally every month until consolidation. At final follow- up of 3-month functional assessment of the patient score was excellent with 90 degrees flexion, an absence of laxity and an absence of pain. Patient was lost to follow up after 3 months.

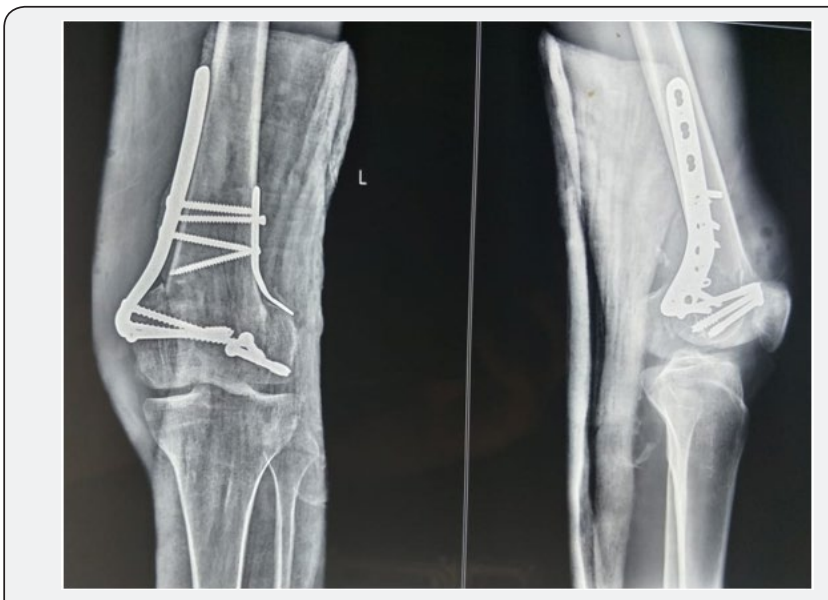

Figure 3: Post-operative radiograph of left knee in Anteroposterior and medio-lateral views with medial and lateral plate and cannulated cancellous screws in situ. 


\section{Discussion}

Hoffa fractures are rare injuries postulated to occur as a result of high-energy mechanism, usually affecting young adults [1]. They usually occur as an isolated injury but bilateral involvement [2] and unilateral bicondylar Hoffa fractures [3] have also been reported. In addition, substantial prevalence of Hoffa fractures in association with supracondylar-intercondylar distal femur fractures have been documented. Partial articular, coronal plane fractures of the posterior part of femoral condyles are rare and account for less than $1 \%$ of distal femoral fractures. Generally, results from trauma secondary to motor vehicle accidents or a fall from a height [4]. High velocity injuries such as road traffic accidents (motor vehicle accidents) are the most common mechanism of injury [4,5]. A high index of suspicion is needed to diagnose these fractures.

Standard AP radiograph may appear unimpressive owing to intact anterior part of condyle; moreover, undisplaced fracture may not be apparent in lateral radiograph. Oblique radiographs and CT scans have been recommended to facilitate the diagnosis of these injuries. CT scan with 3-D reconstruction helps in identifying the exact site of fracture, presence of comminution and assists in preoperative planning. The medial condyle is quite special for our patient as the bibliography suggests that the lateral condyle is most often injured [3,6]. Probably because of following physiologic genu valgus that puts greater compressive stresses on the lateral side. The usual mechanism is postulated to be a combination of vertical shearing and twisting forces. Frontal impact on a flexed knee is more likely to involve the outer aspect resulting in shearing force on the posterior part of lateral femoral condyle.

In these cases, the contribution of the CT scan is undeniable: confirms diagnosis, detect comminution, and research associated injuries. As they are intra-articular fractures, they should be treated by anatomical reduction, rigid internal fixation and early mobilization to restore function. Some authors $[3,5,7]$ recommend open reduction to restore normal condylar anatomy and rigid internal fixation. The articular surface is exposed through a medial or a lateral approach, depending on which condyle is involved. Hoffa fractures are typically reduced and fixed with anterior-posterior or posterior-anterior oriented screws $[3,8,9]$. Problems of this surgical approach are infectious hazards, devascularization and also fragment necrosis. Nowadays treatment with endoscopic mini invasive (Arthroscopic) surgery may reduce its risk. Conservative treatment of Hoffa fracture has some risk: secondary displacement, prolonged immobilization give rise to myoatrophy and joint stiffness.

\section{Conclusion}

In conclusion, we describe a case of a bicondylar medial Hoffa fracture treated successfully with orthopedic method of Internal Fixation. Peculiarity of our case is: the scarcity of its localization, unusually, it is a closed injury. CT scan allowed diagnosis and associated injuries.

\section{References}

1. Lewis SL, Pozo JL, Muirhead-Allwood WFG (1989) Coronal fractures of the lateral femoral condyle. J Bone Joint Surg Br 71(1): 118-120.

2. Heuschen UA, Gohring U, Meeder PJ (1994) Die beidseitige HoffaFraktureine Raritat. Aktuelle Traumatol 24: 83-86.

3. Papadopoulos AX, Panagopoulos A, Karageorgos A (2004) Operative treatment of unilateral bicondylar Hoffa fractures. J Orthop Trauma 18(2): 119-122.

4. Kamal Bali, Aditya Krishna Mootha, Sharad Prabhakar \& Mandeep Singh Dhillon (2011) Isolated Hoffa Fracture of the Medial Femoral Condyle in a Skeletally Immature Patient: a Case Report. Bull NYU Hosp Jt Dis 69(4): 335-338.

5. Manfredini M, Gildone A, Ferrante R, Bernasconi S, Massari L (2001) Unicondylar femoral fractures: therapeutic strategy and long-term results a review of 23 patients. Acta Orthopaedica Belgica 67(2): 132138.

6. Nork SE, Segina DN, Aflatoon K, Barei DP, Henley MB, et al. (2005) The association between supracondylar-intercondylar distal femoral fractures and coronal plane fractures. J Bone Joint Surg Am 87(3): 564569.

7. Miyamoto R, Fornari E, Tejwani NC (2006) Hoffa fragment associated with a femoral shaft fracture. J Bone Joint Surg Am.; 88(10): 22702274.

8. Mounasamy V, Hickerson L, Fehring K, Desai P (2013) Open bicondylar Hoffa fracture with patella fracture: a case report and literature review. European Journal of Orthopaedic Surgery and Traumatology 23(supplement 2): S261-S265.

9. Bali K, Mootha AK, Krishnan V, Kumar V, Rawall S, et al. (2011) A rare case of bicondylar Hoffa fracture associated with ipsilateraltibial spine avulsion and extensor mechanism disruption. Chinese Journal of Traumatology 14(4): 253-256. 


\section{Your next submission with Juniper Publishers} will reach you the below assets

- Quality Editorial service

- Swift Peer Review

- Reprints availability

- E-prints Service

- Manuscript Podcast for convenient understanding

- Global attainment for your research

- Manuscript accessibility in different formats ( Pdf, E-pub, Full Text, Audio)

- Unceasing customer service

Track the below URL for one-step submission https://juniperpublishers.com/online-submission.php 